
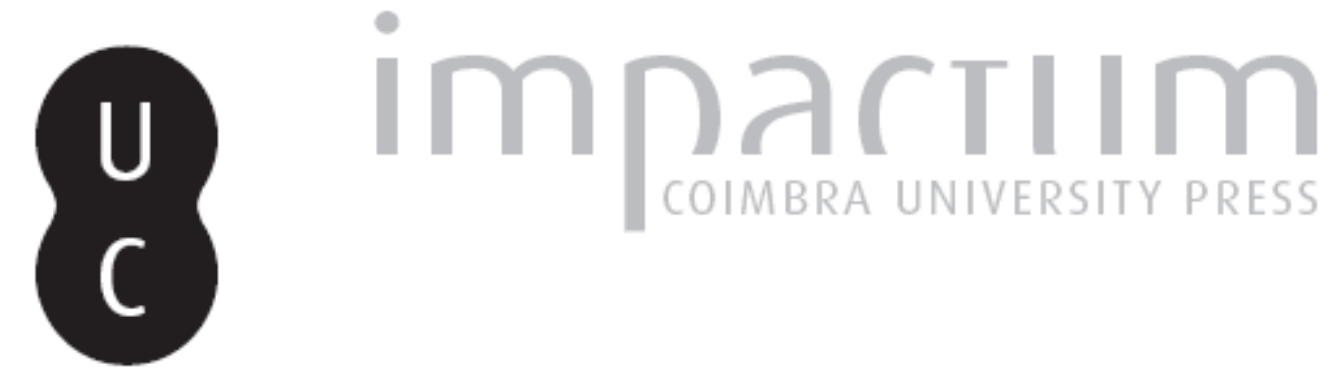

\title{
O serviço integrado das bibliotecas da Universidade de Coimbra: um percurso
}

\author{
Autor(es): $\quad$ Miguéis, Ana Eva
}

Publicado por: Imprensa da Universidade de Coimbra

URL

persistente: URI:http://hdl.handle.net/10316.2/45022

DOI: DOI:https://doi.org/10.14195/1647-8436_48_5

Accessed : $\quad$ 31-Jan-2019 16:02:04

A navegação consulta e descarregamento dos títulos inseridos nas Bibliotecas Digitais UC Digitalis, UC Pombalina e UC Impactum, pressupõem a aceitação plena e sem reservas dos Termos e Condições de Uso destas Bibliotecas Digitais, disponíveis em https://digitalis.uc.pt/pt-pt/termos.

Conforme exposto nos referidos Termos e Condições de Uso, o descarregamento de títulos de acesso restrito requer uma licença válida de autorização devendo o utilizador aceder ao(s) documento(s) a partir de um endereço de IP da instituição detentora da supramencionada licença.

Ao utilizador é apenas permitido o descarregamento para uso pessoal, pelo que o emprego do(s) título(s) descarregado(s) para outro fim, designadamente comercial, carece de autorização do respetivo autor ou editor da obra.

Na medida em que todas as obras da UC Digitalis se encontram protegidas pelo Código do Direito de Autor e Direitos Conexos e demais legislação aplicável, toda a cópia, parcial ou total, deste documento, nos casos em que é legalmente admitida, deverá conter ou fazer-se acompanhar por este aviso.

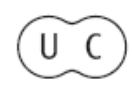




\section{BOLETIM DA \\ BIBLIOTECA GERAL DA UNIVERSIDADE DE COIMBRA}

VOL. 48 (2018)

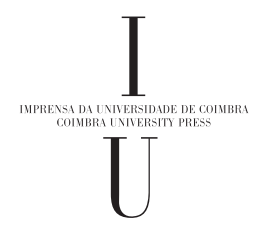




\section{O Serviço Integrado das Bibliotecas da Universidade de Coimbra: um percurso}

Ana Eva Miguéis ${ }^{1}$

\section{RESUMO}

O Serviço Integrado das Bibliotecas da Universidade de Coimbra (SIBUC), estrutura de apoio técnico e de coordenação das bibliotecas da Universidade de Coimbra, tem a missão de criar sinergias entre as bibliotecas, promover a colaboração entre si e dinamizar esforços comuns para a otimização dos recursos existentes e a melhoria da qualidade dos serviços prestados.Com o presente texto pretende-se explicar o que é o Serviço Integrado das Bibliotecas da Universidade de Coimbra (SIBUC), o contexto em que surgiu e em que atualmente intervém, as funções que desempenha, as atividades que promove e que desenha para o futuro.

\section{PALAVRAS-CHAVE}

Bibliotecas; Universidade de Coimbra; Serviço Integrado das Bibliotecas; Gestão de sistemas de informação bibliográficos

1 Bibliotecária e coordenadora do Serviço Integrado das Bibliotecas da Universidade de Coimbra - evamigueis@sib.uc.pt. Orcid.org/0000-0003-2869-7754 


\begin{abstract}
The Integrated Library Service of the University of Coimbra (SIBUC) is a tecnhical structure that coordinates and supports all the libraries of the University of Coimbra, with the aim of creating synergies between libraries and promoting collaboration between them, fostering common efforts for optimization of existing resources and improving the quality of the services provided.This paper intends to explain what is the SIBUC role, the context in which it emerged and activities in which it currently operates, the functions it performs and the activities it promotes and plans for the future.
\end{abstract}

\title{
KEYWORDS
}

Libraries; Coimbra University Integrated Library Service; Bibliographic information systems management.

\section{Introdução}

Ao longo da sua história, a Universidade de Coimbra (UC) criou várias bibliotecas com o objetivo de dar suporte ao ensino e à investigação e tornou-se detentora de um vasto acervo documental. A maior destas bibliotecas é a Biblioteca Geral (BGUC) que possui, só por si, perto de um milhão de volumes, no qual se inclui o riquíssimo património da Biblioteca Joanina, parte importante do fundo de Livro Antigo da Universidade.

As bibliotecas da UC são bibliotecas universitárias - classificadas como bibliotecas especializadas - que se encontram ao serviço da comunidade académica, cabendo-Ihes a missão de apoiar o ensino, a investigação e a difusão de cultura, vertentes que caracterizam as instituições de ensino superior. Compete-Ihes reunir, organizar, tratar, tornar acessível, divulgar a informação e promover o conhecimento, reconhecendo-se-lhes "primordial importância para o bom funcionamento da Universidade, tanto para docentes e investigadores como para alunos e até para funcionários. Constitui ainda um importante meio para 
prestação de serviço à comunidade, como é missão das universidades modernas (Marques, et al, 2006, p. 6).

Durante as últimas décadas as bibliotecas sofreram numerosas transformações, nomeadamente nos anos de 1980 e 1990 em que se assistiu, do ponto de vista técnico e organizacional, a mudanças que resultaram do desenvolvimento e difusão das novas tecnologias da informação e comunicação. Em primeiro lugar, destaca-se o uso sistemático e generalizado do computador, que permitiu a melhoria dos sistemas usados nas bibliotecas, através da automatização de novas operações. Pela mesma altura, apareceram os primeiros sistemas integrados de gestão de bibliotecas (ILS) com módulos integrados que possibilitaram a partilha de informação, a eliminação de redundâncias, evitando a duplicação de dados e reduzindo o esforço consagrado às tarefas técnicas (Ferreira, 2014, 16). Mais tarde, o aparecimento da Internet conduziu ao catálogo público em linha (OPAC)2 "que revolucionou a forma de pesquisa nos catálogos das bibliotecas. A rede mundial que se estabeleceu com a Internet potenciou a catalogação em linha, a partilha de dados e o aparecimento das primeiras bases de dados bibliográficos" (Ferreira, 2014, 16). Os bibliotecários souberam sempre, ainda que com esforço, ajustar-se a estas mudanças e desenvolver novas competências para responder de forma assertiva às necessidades da comunidade académica, cada vez mais familiarizada com as novas tecnologias.

\section{Análise da situação das Bibliotecas da UC}

Apesar destas mudanças, que permitiram melhorias consideráveis no plano do trabalho, as bibliotecas da UC sentiam a necessidade de proceder a uma reformulação dos seus serviços, para que conseguissem dar resposta ao que delas se esperava, transformando-se

2 O acrónimo OPAC refere-se à expressão em inglês "Online Public Access Catalog". 
num "grande espaço multimédia" (Marques et al., 2006, 6) que lhes permitiria disponibilizar serviços não apenas durante o seu período de funcionamento, mas também à distância, correspondendo melhor a metodologias de ensino, aprendizagem e investigação. Do mesmo modo, o número de bibliotecas universitárias polvorizara-se de tal modo que a sua articulação era pouco eficaz e era indispensável avançar com uma reorganização dos serviços, unindo alguns deles e alterando outros. A esta preocupação juntavam-se ainda dois constrangimentos: o facto de as instalações das bibliotecas serem pouco flexíveis e não se ajustarem às alterações pretendidas e a circunstância de os espaços destinados aos depósitos se encontrarem saturados.

Por outro lado, a coordenação entre as bibliotecas não era a mais desejável, resultando numa arbitrariedade de horários para a leitura presencial e na utilização de diferentes sistemas informáticos de suporte ao catálogo. Esta situação criava diferentes formas de pesquisa e de requisição de obras, sem que existisse qualquer ligação aos catálogos das restantes bibliotecas, dentro da mesma instituição.

A reflexão sobre a missão das bibliotecas universitárias e a sua adequação às novas exigências há muito que se fazia sentir, mas era essencial adotar um plano concreto de reestruturação, pressupondo uma nova gestão de recursos e, paralelamente, a integração e coordenação de serviços (Marques et al, 2006, 6). Esta gestão de recursos passava pela otimização de espaços e equipamentos e implicava uma nova abordagem da gestão que pretendia garantir o reaproveitamento dos recursos bibliográficos e humanos e a adequação dos espaços e equipamentos de modo a servir eficazmente os utilizadores das bibliotecas: salas para leitura, salas para estudo, depósitos para publicações. Tal significava criar ou melhorar salas de leitura nas bibliotecas, com o objetivo de as dotar de espaços de consulta e acesso aos documentos, permitindo o empréstimo e a devolução de obras, independentemente da biblioteca onde se localizassem. A gestão dos recursos bibliográficos implicava um 
reforço dos sistemas que facilitassem o seu acesso, como era o caso da conversão de catálogos para suporte informático, a adoção de uma política comum para a aquisição de publicações, a simplificação da circulação de documentos e de utilizadores pelo universo das bibliotecas através de um regulamento comum de empréstimo domiciliário e de empréstimo interbibliotecas.

Assumindo um papel de liderança, a Biblioteca Geral conduziu um processo de informatização que passou por diversas fases e abordou diferentes sistemas de gestão de bibliotecas, ao longo das últimas décadas. Foi um processo longo, mas que contemplou, desde o seu início, a totalidade das bibliotecas da Universidade de Coimbra ${ }^{3}$. Nos finais da década de 1990, inaugurou-se o primeiro catálogo coletivo informatizado da Universidade de Coimbra, com o sistema Libertas. Este agregava, para além do catálogo da BGUC, os registos bibliográficos oriundos dos sistemas locais das bibliotecas das Faculdades de Letras, Ciências e Tecnologias (Arquitetura, Matemática e Engenharias), Economia, Psicologia, Ciências do Desporto e dos Hospitais da UC. Pela primeira vez, as bibliotecas da UC passaram a dispor de um só catálogo público em linha (OPAC) (Ferreira, 2014, p. 45). Foi este sistema partilhado de catalogação e de gestão do empréstimo que deu origem à base de dados bibliográficos comum da Universidade, que se designa por Sistema Integrado de Informação Bibliográfica da Universidade de Coimbra (SIIB/UC). No entanto, foi apenas no início do novo milénio, com a aquisição do sistema Millennium, que se alcançou o catálogo integrado das bibliotecas da UC que hoje se conhece.

Como resposta à situação que as bibliotecas da UC viviam nos finais da década de 1990 e inícios da seguinte, propôs-se, então, um plano geral de reorganização e reestruturação das bibliotecas,

3 Poderá ler mais sobre o processo de informatização das bibliotecas da Universidade de Coimbra, no trabalho de Carla Ferreira, "A Automatização da(s) Biblioteca(s) da Universidade de Coimbra". 
que envolvia o reagrupamento de bibliotecas, o reforço do papel da Biblioteca do Conhecimento Online (b-on), a criação de um serviço integrado das bibliotecas e por uma nova gestão de recursos, integração e coordenação de serviços. Este plano foi apresentado num relatório sobre a reorganização e reestruturação das bibliotecas da Universidade de Coimbra (Marques et al., 2006), com a supervisão da Reitoria da UC e elaborado por uma comissão que envolvia o diretor da Biblioteca Geral, docentes universitários e bibliotecários da Universidade de Coimbra e de outras universidades, como a do Porto e Salamanca.

\section{Gestão de recursos das Bibliotecas da UC}

A experiência e o contacto com outras bibliotecas universitárias, em Portugal e no estrangeiro, e os trabalhos produzidos sobre bibliotecas universitárias contribuíram para a perceção de que a existência de uma estrutura de apoio técnico e de coordenação para as bibliotecas correspondia ao interesse da própria Universidade. Reconhecia-se que a melhoria da qualidade das bibliotecas passaria por estabelecer uma orientação geral, implicando a centralização e a administração de produtos e de serviços comuns. Esta convicção era reforçada pela rápida evolução de novas soluções técnicas, a necessidade de formar de modo apropriado os profissionais, adequando as respostas às questões colocadas quer por eles, quer pelos seus utilizadores.

As propostas apresentadas no plano de reorganização e reestruturação das bibliotecas da UC constituíram-se em redor de quatro áreas de intervenção: reagrupamento de bibliotecas, reforço do papel da Biblioteca do Conhecimento Online (b-on), criação de um serviço integrado das bibliotecas e gestão de recursos, integração e coordenação de serviços. 
Do que já atrás se referiu, a gestão de recursos pressupunha a otimização de espaços e equipamentos e obrigava a uma reorganização das próprias bibliotecas, procurando adequá-las às necessidades dos utilizadores. Tal significava criar ou melhorar salas de leitura nas bibliotecas, com o objetivo de as dotar de espaços de consulta e acesso aos documentos, permitindo o empréstimo e a devolução de obras, independentemente da biblioteca onde se localizassem. Esta reforma também incluía uma redução progressiva do número de bibliotecas, ajustando os horários de funcionamento de modo articulado, o que permitiria o funcionamento em rede e rentabilizar os recursos bibliográficos e humanos existentes. Para além das salas de leitura era necessário disponibilizar salas de estudo nos vários polos da Universidade, com horários mais alargados e com condições de apoio ao estudo, permitindo a utilização de computadores e a ligação Wireless. Outra preocupação com os espaços envolvia os depósitos, defendendo a disponibilização de um espaço comum ou a construção de um silo que permitisse libertar as áreas das bibliotecas das publicações menos consultadas, de duplicados, ou daquelas que já é possível consultar em outros suportes, como o digital.

A gestão e o reforço dos recursos humanos foram também questões centrais deste relatório. Impunha-se a definição de um plano de formação adequado que permitisse a atualização de conhecimentos e a melhoria de competências no domínio das novas tecnologias e no âmbito de novas funções que poderiam vir a ser desempenhadas pelas bibliotecas. Do mesmo modo referia-se a reconversão de pessoal e a sua especialização na área das bibliotecas, advogando-se a partilha de recursos e a cooperação como forma de racionalizar recursos. Previa-se até a contratação de serviços externos para tarefas temporárias de grande volume, como a reconversão dos registos bibliográficos em formato eletrónico. 
No que dizia respeito à gestão da informação, o plano de reestruturação preconizava a implementação completa do sistema integrado de gestão bibliográfica com o Millenium, que asseguraria o funcionamento do SIIB/UC e realizaria de forma consistente e coordenada a gestão de toda a informação em formato digital. A existência de regulamentos comuns para o empréstimo domiciliário ou para o empréstimo interbibliotecas tornava-se possível com a adoção deste sistema em todas as bibliotecas da UC e a existência de um cartão de identificação único para a utilização dos serviços prestados pelas bibliotecas, reconhecido por todas elas, permitiria agilizar a circulação no seio da comunidade académica.

No mesmo documento, defendia-se, também, a integração de todos os recursos digitais da UC e o fomento de edições em formato eletrónico, elegendo este formato como preferencial para o acesso à informação e com vantagens para uma política de aquisições de publicações em formato digital. Este formato serviria, ainda, para a apresentação da produção científica e pedagógica dos autores ligados à UC e para a criação de suportes digitais que preservassem a documentação original em papel.

Um portal de informação relativa às bibliotecas e aos seus serviços, com ligações aos recursos digitais existentes, como o catálogo ou a b-on, completaria esta vertente de gestão.

Em suma, o plano de reestruturação e reorganização gizado pretendia determinar as áreas em que era urgente intervir e que, uma vez reformadas, levariam a ganhos significativos de eficiência dos serviços e da sua articulação. O novo sistema organizativo das bibliotecas da UC deveria assentar numa estrutura em rede, "em que as diferentes bibliotecas se organizarão como nós da mesma, mantendo um funcionamento aberto e expansivo" (Marques et al., 2006, 28). O problema da organização das bibliotecas, reconhecido pela Reitoria e confirmado pelos trabalhos da Comissão, recomendava, pois, a criação de um serviço apropriado que, articulado com as 
funções da BGUC, possibilitaria a otimização de meios e recursos existentes ou a produzir.

\section{Criação do Serviço Integrado das Bibliotecas da Universidade de Coimbra}

Deste modo, após a conclusão da análise sobre a situação das bibliotecas da UC e com a apresentação das propostas fundamentadas da Comissão que elaborou o Relatório, o Senado, sob proposta do Reitor, promulgou a Deliberação n. $75 / 2006$, que aprovou este documento e autorizou a criação de uma estrutura de apoio e coordenação das suas bibliotecas: o Serviço Integrado das Bibliotecas da Universidade de Coimbra (SIBUC). Em dezembro de 2009 foi publicado o Regulamento n. ${ }^{\circ}$ 488/20091 em Diário da República, com o objetivo de prover o SIBUC com um conjunto de normas de organização e funcionamento que lhe permitisse articular-se de forma coerente com a nova realidade orgânico funcional.

O Serviço Integrado das Bibliotecas da Universidade de Coimbra (SIBUC) apresentava-se, então, como resposta às questões colocadas no relatório das bibliotecas universitárias, com um modelo alternativo à organização existente até aí nas bibliotecas da UC, ou seja, procurava afirmar uma gestão centralizada de recursos, serviços e de algumas funções relacionadas com estes serviços, que coubessem nas suas competências. O modo circunstanciado como surge a descrição das funções atribuídas, a dependência hierárquica, a localização e estrutura apresentadas no Relatório dão conta da centralidade que era reconhecida a este Serviço no conjunto de bibliotecas.

O SIBUC surge, assim, como uma estrutura de apoio técnico e de coordenação das bibliotecas da Universidade de Coimbra, com a missão de criar sinergias entre as bibliotecas, promover a colaboração entre todas elas e dinamizar esforços comuns para a otimização dos recursos existentes na área técnica e na melhoria da qualidade 
dos serviços prestados. Compete-lhe, ainda, apoiar as bibliotecas na melhoria da qualidade dos serviços, apresentando-se como um órgão indispensável à coordenação dos serviços das bibliotecas em toda a Universidade. Deverá, também, proporcionar estudos que facilitem a integração física ou virtual de diferentes bibliotecas e desenvolver a sua atividade com os recursos humanos e financeiros que a Universidade colocar à sua disposição.

As funções definidas para o SIBUC cobrem um conjunto de tarefas que envolvem 14 áreas de intervenção ${ }^{4}$ :

- Coordenar o Sistema Integrado de Informação Bibliográfica da UC (SIIB/UC);

- Apoiar a Biblioteca do Conhecimento Online (b-on);

- Coordenar a gestão e disponibilização das bases de dados comuns da UC, assim como as assinaturas de publicações periódicas (em papel ou eletrónicas), com base nas existências da b-on;

- Gerir o Estudo Geral, o repositório digital da produção científica da UC;

- Apoiar na UC a manutenção da Biblioteca Aberta do Ensino Superior (BAES), destinada a estudantes do ensino superior com necessidades educativas especiais;

- Gerir a Biblioteca Digital da UC;

- Propor, em colaboração com os serviços de natureza central da Universidade no domínio das tecnologias da informação e comunicação, as alterações e investimentos necessários à atualização de equipamentos e sistemas informáticos e infraestruturas de suporte aos recursos de informação geridos pelo SIBUC, e que por ele são mantidos;

4 Funções indicadas no Regulamento do Serviço Integrado das Bibliotecas da Universidade de Coimbra (SIBUC). Publicado em Dário da República. 2009. 2a Série: № 238, p. 49902-03. 
- Apoiar a preservação do património bibliográfico da UC, com os adequados procedimentos técnicos e a promoção do desenvolvimento de serviços de restauro comuns;

- Estudar e propor procedimentos harmonizados entre as bibliotecas da UC para dar cumprimento a exigências legais;

- Elaborar candidaturas e gerir projetos, em articulação com os serviços de natureza central da Universidade em matéria administrativo-financeira, para financiamento, interno e externo, da modernização em equipamento e tecnologia das Bibliotecas da UC;

- Elaborar estudos para racionalizar, redistribuir e, em alguns casos, propor a eliminação, designadamente de duplicados, dos recursos documentais das Bibliotecas da UC;

- Prestar serviço de consultadoria e apoio às Bibliotecas da UC, quando para isso solicitado;

- Prestar assessoria técnica à Reitoria, na área das Bibliotecas, nomeadamente dando pareceres relativos à aquisição, manutenção e alteração das infraestruturas das bibliotecas (edifícios, mobiliário, iluminação, etc.), assim como à sua dotação financeira e fornecimento dos dados estatísticos necessários para fundamentar decisões no âmbito das Bibliotecas da UC, em particular no respeitante ao seu progressivo agrupamento; - Assegurar a manutenção do Portal das Bibliotecas da UC, meio online que reúne informação bibliográfica e documental de interesse comum.

Algumas das áreas de intervenção referidas, como são os casos da coordenação do SIIB/UC, o apoio da b-on, a gestão de Estudo Geral ou a gestão da biblioteca digital, desdobram-se em várias ações complementares, compreendendo todas elas a promoção de ações de divulgação e formação para utilizadores.

Infere-se então, do que se expõe, que o SIBUC tem sob a sua responsabilidade um leque de atribuições que exigem um elevado 
grau de competências técnicas e uma adequada preparação dos seus profissionais, de modo a conseguir responder às questões que Ihe possam vir a ser colocadas. Naturalmente que o facto de esta estrutura ser acolhida na BGUC significa que por "razões históricas, regulamentares e funcionais ${ }^{5}$ " os recursos adicionais de que venha a necessitar serão partilhados entre as duas organizações e que existirá uma articulação privilegiada e necessária entre ambas. Daqui se pode deduzir que este novo serviço deve ser dotado de uma estrutura leve e capaz de criar sinergias com os outros serviços da Universidade, com uma equipa dedicada e com um perfil nas áreas de biblioteca e informática.

\section{Implementação e funcionamento do SIBUC}

O SIBUC foi apresentado publicamente a 19 de julho de 2007 e iniciou o seu funcionamento no mesmo ano, antes ainda de ver publicado o seu Regulamento, que veio a lume em dezembro de 2009. O início do processo de recrutamento de pessoal para integrar este Serviço foi autorizado com a publicação do Despacho Reitoral $n^{\circ}$ 46/2007. Dentro das suas competências e da sua dimensão, a equipa tem procurado ao longo destes últimos 10 anos verter para a prática o que o Regulamento define e articular de forma centralizada a administração das atividades a seu cargo, dando conta da sua execução através de relatórios de atividades e em reuniões de bibliotecas, que organiza anualmente.

Das atividades que desenvolve com regularidade e que procuram responder às suas atribuições, faz-se agora uma breve referência a algumas delas, reforçando as que se revelam como mais estruturantes para o universo das bibliotecas e para a própria Universidade.

5 Conforme se pode ler no Preâmbulo do Regulamento do SIBUC. 


\section{a) Sistema Integrado de Informação Bibliográfica da Universidade de Coimbra (SIIB/UC)}

A coordenação do SIIB/UC começou por ser a principal atribuição do SIBUC, mas hoje o sistema adquiriu uma dinâmica própria a todos os níveis, encontrando-se a funcionar de modo regular. $\mathrm{O}$ sistema Millennium, sistema adotado pelas Bibliotecas da UC, veio "responder às necessidades de gestão bibliográfica sentidas e manifestadas pelas bibliotecas da UC, melhorando assim o seu atendimento ao público, satisfazendo cada vez mais e melhor as suas necessidades de informação (Ferreira, 2014, 28). Este sistema permitiu a uniformização de procedimentos nas várias bibliotecas do SIIB/UC - como é o caso dos regulamentos aplicados ao empréstimo domiciliário ou ao empréstimo interbibliotecas - contribuiu para a racionalização das tarefas técnicas e para o controlo das aquisições, permitindo a redução de custos e o aumento da consistência e uniformidade do catálogo. Além disso, garantiu a utilização do cartão de identificação institucional (de estudante e de funcionário), tornando desnecessária a manutenção de um cartão próprio, usado para as bibliotecas.

O SIBUC assegurou a parametrização do sistema Millennium e tem vindo a implementar novas versões e funcionalidades, como é o caso dos módulos de autoemprestimo, adotados pela Biblioteca da Faculdade de Psicologia (em 2012) e pela Faculdade de Letras (em 2016). A gestão da base de dados bibliográfica é feita em colaboração com a BGUC, assim como a coordenação e normalização dos procedimentos técnicos. A formação técnica dos profissionais de bibliotecas, necessária ao bom funcionamento do sistema tem sido realizada sempre que necessário, contando com o apoio da BGUC e de elementos dos Grupos de Trabalho. Estes Grupos de Trabalho, compostos por bibliotecários das bibliotecas participantes e da BGUC, foram constituídos para estudar, apoiar a implementação e preparar a formação em cada um dos módulos do Millennium (catalogação, 
empréstimo domiciliário, publicações periódicas, OPAC, empréstimo interbibliotecas), para todas as bibliotecas que integram o SIIB/UC - incluindo as instituições externas à UC, como o Centro Hospitalar Universitário de Coimbra ou a Escola Superior de Enfermagem de Coimbra. Indica-se, a este propósito, a atividade mais recente (em 2015) desenvolvida pelo Grupo de Trabalho da Catalogação, que conduziu à implementação da descrição bibliográfica baseada na ISBD Consolidada.

O número de bibliotecas na UC que tem vindo a ser reagrupado ao longo dos últimos anos - o que corresponde a uma das reformas enunciados no Relatório sobre a reorganização das bibliotecas resulta na redução das bibliotecas departamentais, traduzindo-se tecnicamente, numa reconfiguração e extensão no Millennium. Convém mencionar que o processo de reagrupamento das Bibliotecas se iniciou logo após as recomendações do Relatório. Primeiro, com a construção da nova Biblioteca das Ciências da Saúde, no Polo III, que ficou a dar suporte às Faculdades de Medicina e de Farmácia (2009); mais tarde, com a constituição da Biblioteca do Polo II (2013) destinada a apoiar os departamentos de Engenharias (Engenharias Química, Informática, Eletrotécnica, Mecânica e Civil e, mais tarde, as Ciências da Terra), que reorganizou os recursos existentes em todos os departamentos e centralizou os seus serviços na precedente Biblioteca de Engenharia Civil; no ano seguinte (2014), a constituição da Biblioteca das Ciências da Vida (agregando as antigas bibliotecas de Botânica, Antropologia, Zoologia e Bioquímica) e a Biblioteca de Física e Química que resultou da integração dos núcleos documentais do Departamento de Física e do Departamento de Química. Em todos estes momentos de transição o trabalho dos bibliotecários e dos técnicos das Bibliotecas neles envolvidos, realizou-se com notável zelo e dedicação, sem o qual não teria sido possível qualquer mudança.

Como indicadores de referência do movimento do catálogo integrado, o número médio anual de novos registos acrescentados ao 
catálogo cifra-se perto dos 49.000 e o movimento médio de circulação anual ultrapassa os 110.500 empréstimos domiciliários ${ }^{6}$, conforme as Figuras 1 e 2 indicam:

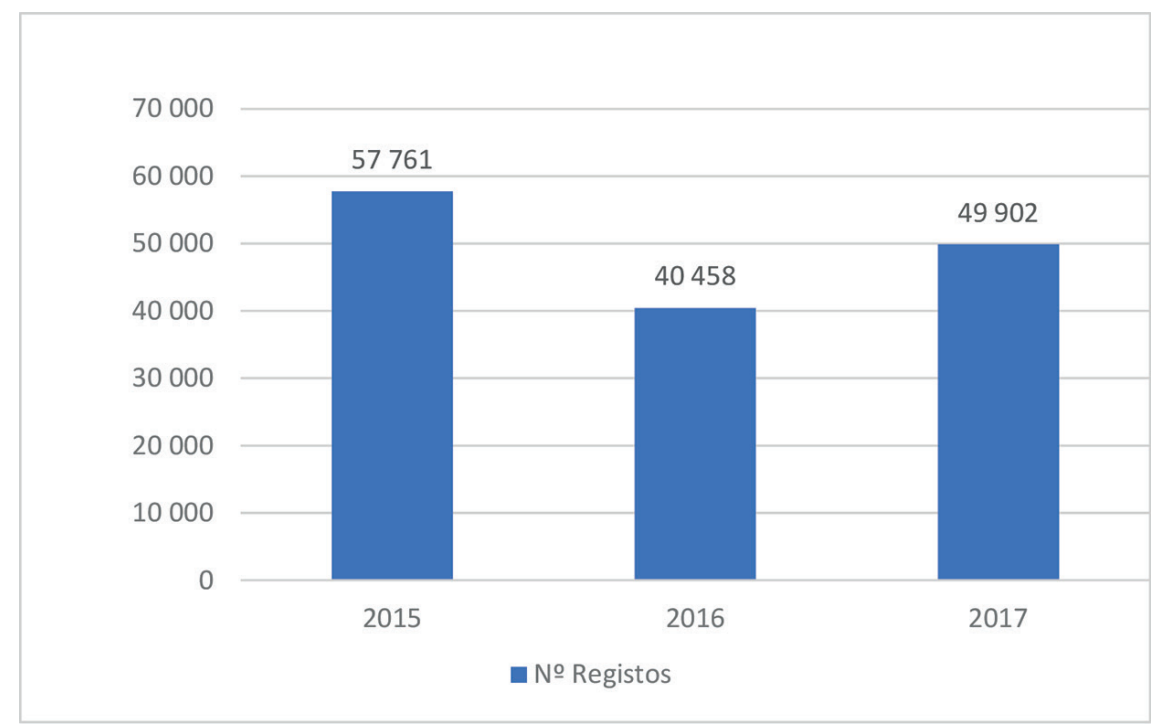

Figura 1 - Novos registos no catálogo (2015 a 2017)

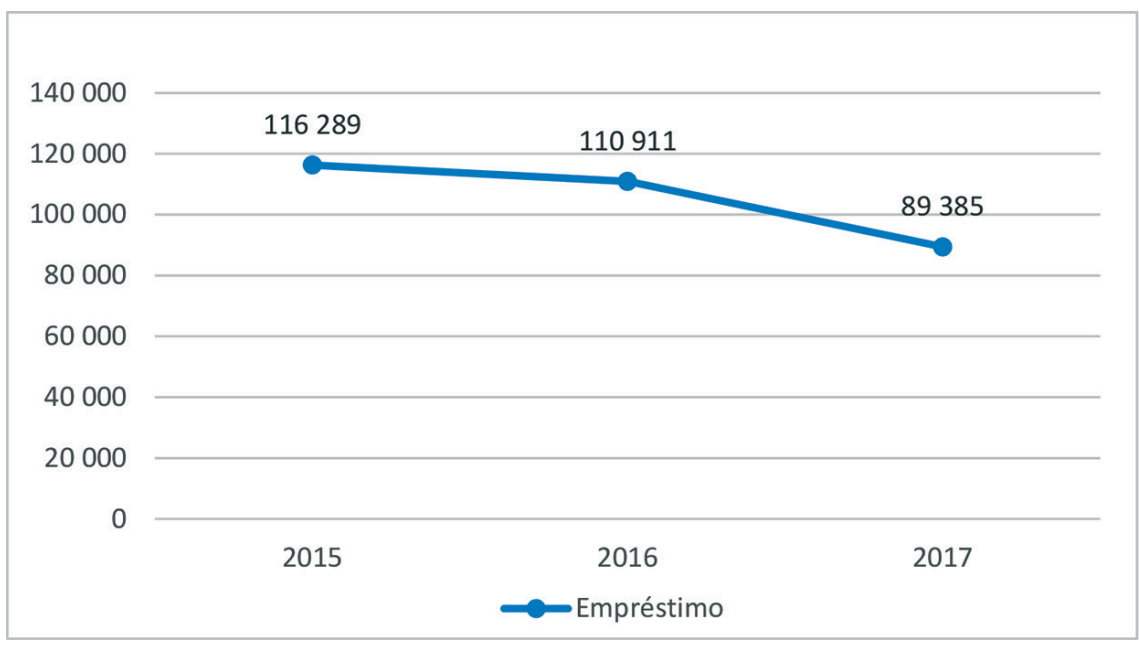

Figura 2 - Empréstimo domiciliário (2015 a 2017)

6 Ambas as médias foram obtida com base nos números registados para os anos de 2015, 2016 e 2017. 


\section{b) Repositório digital Estudo Geral}

O Estudo Geral foi apresentado publicamente em 2008, com a missão de divulgar a produção científica dos autores ligados a esta instituição, promover a sua visibilidade, guardar e preservar a memória intelectual num único sítio, de forma estruturada e facilmente recuperável. Em outubro de 2010 foi aprovada a "Política de Acesso Livre (Open Access) da Universidade de Coimbra"7 que estabelece que o depósito de toda a produção científica da UC seja feito no Estudo Geral. Cada um dos membros intervenientes neste processo - o Serviço de Gestão Académica, as Bibliotecas e o SIBUC - desempenham um papel essencial para a concretização de tal política. Embora todas as bibliotecas sejam importantes para a prossecução deste processo, é ao SIBUC que cabe coordenar, dinamizar e gerir todo um conjunto de atividades que criam as condições para que os docentes e investigadores da UC façam do autodepósito uma atividade regular.

O número de documentos depositados no Estudo Geral tem vindo a aumentar de forma sustentada ao longo dos anos, situando-se atualmente num valor acima dos $30.000^{8}$ documentos, distribuídos de acordo com o que vem indicado na Figura 3. Este crescimento tem vindo a ser mais significativo no que respeita a dissertações (34\%), aos artigos em publicações periódicas nacionais e internacionais (31\%) e às teses de doutoramento (19\%) e o conjunto de documentos disponibilizado em acesso aberto representa hoje perto de $80 \%$ do total de documentos depositados. No mesmo sentido, os dados disponibilizados no Estudo Geral, que identificam o número de pesquisas,

7 Esta Política está disponível para consulta em https://www.uc.pt/regulamentos/ transversais/vigentes/politica_acesso_livre_open_access_da_uc.pdf

8 Todos os dados indicados foram retirados das estatísticas do Estudo Geral. [consult. 23 abr. 2018] 
consultas e downloads, têm registado um aumento na utilização do repositório, com downloads que se situam perto dos 350.000 por mês.

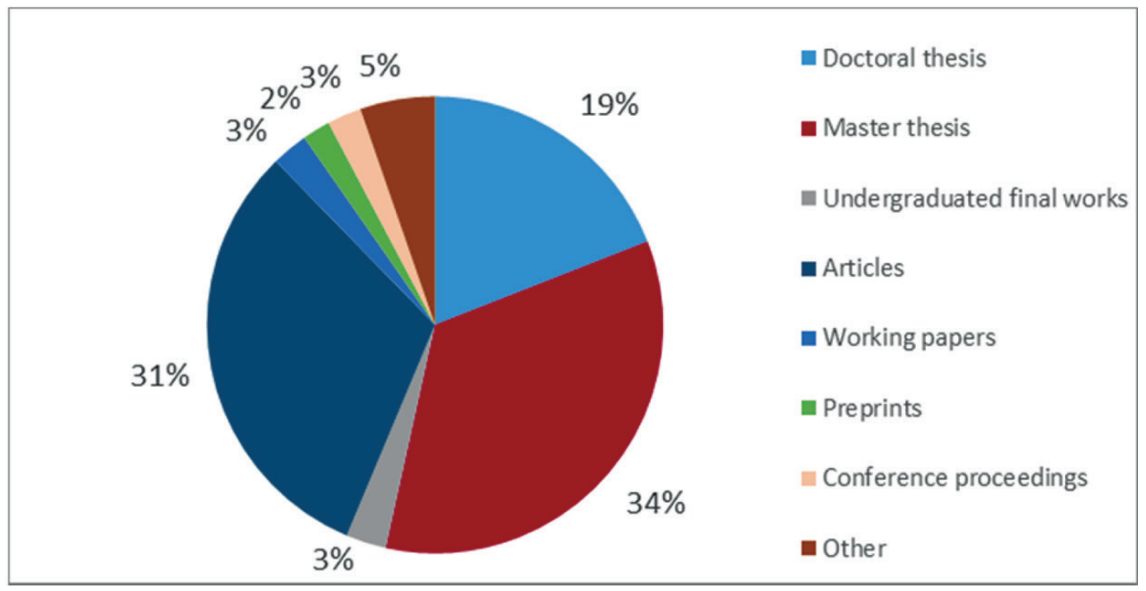

Figura 3 - Distribuição de depósitos por tipologia documental (2017)

A gestão do Estudo Geral implica todos os aspetos de administração do sistema informático e a implementação de novas versões e funcionalidades, o que já aconteceu por duas vezes e que garante a interoperabilidade do Estudo Geral com o Repositório Científico de Acesso Aberto de Portugal (RCAAP).

O SIBUC é o interlocutor da UC com o RCAAP e, nessa função, participa nas reuniões de coordenação deste órgão que decorrem duas vezes por ano; em iniciativas promovidas anualmente pela Semana Internacional do Acesso Aberto que se assinala durante o mês de outubro; nas Jornadas anuais da FCT/FCCN; na Conferência Luso-brasileira sobre Acesso Aberto que decorre todos os anos, das quais se destaca a que decorreu em Coimbra, em 2014; em grupos de trabalho do RCAAP, em que tem assumido a coordenação nacional de alguns grupos de trabalho, como é o caso do Grupo de Divulgação do RCAAP (desde 2016). 
Na Política de Livre Acesso da UC indicam-se as competências que cabem a cada um dos serviços da UC para a concretização dos objetivos enunciados neste documento, reforçando-se o papel do SIBUC e sua ligação com os Serviços de Gestão Académica (SGA) e secretarias de Assuntos Académicos das várias unidades orgânicas, conduzindo à uniformização de procedimentos. Desde 2013 que a gestão das coleções das provas de doutoramento e das provas de agregação se faz a partir da plataforma informática do Estudo Geral (DSpace), com a vantagem de facilitar o acesso e promover a desmaterialização dos documentos. Mais recentemente, com a aplicação da Portaria 285/2015', a colaboração com os SGA intensificou-se e permitiu a ligação e interoperabilidade do Estudo Geral com o sistema NONIO, utilizado na gestão académica da UC, possibilitando aos alunos do $2^{\circ}$ ciclo a introdução dos metadados e dos trabalhos de mestrado no InforEstudante, a plataforma de apoio aos estudantes, garantindo que através desta via fiquem depositados no Estudo Geral.

\section{c) Biblioteca digital Alma Mater}

A Alma Mater ${ }^{10}$, biblioteca digital de Fundo Antigo da Universidade de Coimbra, congrega várias bibliotecas digitais das unidades orgânicas da UC, como a "Biblioteca Digital da Faculdade de Direito", a "Biblioteca Digital da Faculdade de Letras", a "Biblioteca Digital de Botânica da Faculdade de Ciências e Tecnologia", a "Biblioteca Geral Digital", ou temáticas como a "República Digital", "História da Ciência"

9 A Portaria 285/2015 veio regulamentar o artigo 50 do Decreto-Lei n. ${ }^{\circ}$ 115/2013 que define como obrigatório o depósito legal de uma cópia digital das teses de doutoramento ou de outros trabalhos apresentados para obtenção do grau de doutor e das dissertações de mestrado num repositório integrante da rede RCAAP.

10 A biblioteca digital Alma Mater está disponível em https://almamater.sib.uc.pt/. 
ou "500 Anos da Biblioteca da Universidade de Coimbra"11 e resultou de diversos projetos financiados por entidades nacionais e fundos próprios da Universidade. A Alma Mater compreende uma coleção de cerca de 5.600 obras e perto de 2.000 .000 imagens digitalizadas e encontra-se apetrechada de um conjunto de funcionalidades que permitem ao utilizador, para além da navegação, realizar uma pesquisa fácil a todos os seus recursos.

Procurando seguir uma estratégia de desenvolvimento e modernização, esta biblioteca digital foi integrada na plataforma UC Digitalis $^{12}$, plataforma desenvolvida pela equipa do SIBUC para dar resposta a um pedido expresso pela Imprensa da Universidade de Coimbra (IUC), em 2011, que pretendia acomodar os suportes digitais das suas publicações. Neste desígnio, através da agregação e difusão de conteúdos digitais em língua portuguesa procurou-se promover a ligação da Universidade com o país e o mundo. O projeto UC Digitalis resultou, então, de uma parceria com a IUC e possibilitou a agregação de três bibliotecas digitais: Alma Mater - biblioteca digital de fundo antigo das bibliotecas da UC, Pombalina - biblioteca digital que disponibiliza toda a produção editada pela Imprensa da Universidade de Coimbra - e Impactum - biblioteca digital de publicações periódicas da UC, mas aberta à colaboração de outras revistas lusófonas. Durante vários anos, o SIBUC consagrou grande parte dos esforços no desenvolvimento e manutenção da UC Digitalis, projeto considerado de grande relevância para a promoção e divulgação de ciência em língua portuguesa, com especial relevo para as Ciências Sociais e Humanas. Pela projeção alcançada, foi estabelecido um protocolo entre a UC e a Fundação para a Ciência e a Tecnologia (FCT) em 2014 que permitiu a integração da UC Digitalis na b-on e a sua divulgação junto das instituições membro b-on. Para que

11 Pode ver estas bibliotecas digitais associadas em https://almamater.sib.uc.pt/ pt-pt/bibliotecas_digitais.

12 A UC Digitalis está disponível em https://digitalis.uc.pt/ 
fosse consumada essa integração, o SIBUC adequou um conjunto de requisitos técnicos obrigatórios e os serviços ficaram instalados em dois servidores virtuais alojados na infraestrutura da FCCN, pelo que a satisfação de alguns dos requisitos decorre dessa circunstância.

O SIBUC tem ainda a seu cargo a intervenção na manutenção e gestão de outras bibliotecas digitais, como é o caso da BAES - Biblioteca Aberta do Ensino Superior e da Classica Digitalia, que em 2016 passou a estar disponível na UC Digitalis ${ }^{13}$.

\section{d) Participação em projetos}

Ao longo destes 10 anos, o SIBUC apoiou candidaturas e submeteu alguns projetos em colaboração com outras estruturas, em particular com a Biblioteca Geral. Alguns desses projetos foram aprovados, como aconteceu com o projeto "Catálogo da Biblioteca Científica do Doutor Luís de Albuquerque", aprovado pela Fundação Calouste Gulbenkian (2009) ou os projetos "Tratamento e digitalização do Fundo do Instituto de Coimbra" (2008) e "História da Ciência da Universidade de Coimbra e História da Ciência Botânica", no âmbito do Programa em História da Ciência (2009), ambos financiados pela FCT.

Mais recentemente, o SIBUC tem vindo a participar no projeto "IES em Rede" (2016), que integra um consórcio de instituições de Ensino Superior, numa das vertentes do projeto que se relaciona com a definição de um sistema de gestão de ciência para a UC (CRIS), a desenvolver em parceria com os das outras instituições envolvidas. Neste projeto, o repositório digital da UC ganha novos contornos e funcionalidades e fornece suporte para a infraestrutura de rede que permitirá criar um CRIS.

13 O endereço de acesso à Biblioteca "Classica Digitalia" é https://classicadigitalia.uc.pt 


\section{e) Ligação com a b-on}

O SIBUC é o interlocutor da b-on na Universidade de Coimbra e mantém contactos regulares com a FCT em todos os assuntos relacionados com a B-on na UC. Divulga pelas bibliotecas toda a informação que lhe é remetida, como seja a comunicação de períodos de acesso gratuito a novas bases de dados ou a publicações eletrónicas disponibilizadas pelos editores aos membros b-on, a comunicação de estatísticas associadas à utilização destes recursos, apoia contactos para assinaturas de novos conteúdos ou para ações de formação direcionados a toda a comunidade académica, promovendo a utilização da b-on na UC.

\section{f) Atividades de formação}

Outras iniciativas têm sido organizadas, individualmente ou em colaboração, como sessões de formação e Workshops, com o objetivo de satisfazer necessidades de formação dos profissionais das bibliotecas da UC e necessárias ao bom funcionamento dos serviços e sistemas adotados. Para a divulgação de novos produtos ou para a utilização informada dos mais recentes, promove sessões em colaboração com editores ou livreiros, quer para as bibliotecas, quer para a comunidade universitária. Neste ponto interessa salientar a relevância de novas funções que devem ser desempenhadas pelas bibliotecas, como é o caso das competências que hoje se exigem no domínio da Ciência Aberta, dos Direitos de Autor ou no apoio à publicação científica.

De igual modo, organiza reuniões de trabalho anuais com todas as bibliotecas da Universidade de Coimbra, onde se apresenta e discute o relatório de atividades e o plano de atividades, nas quais participam o Diretor da BGUC e SIBUC e o Vice-Reitor para a área das bibliotecas. 
Numa perspetiva de formação e ensino em contexto de trabalho, o SIBUC promove a colaboração internacional, acolhendo colegas estrangeiros, muitos deles no âmbito do Programa Erasmus e em articulação com a Divisão de Relações Internacionais, organizando visitas às bibliotecas da UC e reuniões de partilha de experiências. Tem recebido colegas de diferentes países, de modo particular da Polónia e Espanha, mas também da Grécia, Itália, Republica Checa, Alemanha e Brasil.

\section{g) Outras atividades}

Numa outra vertente, o SIBUC para monitorizar as várias solicitações que lhe são feitas, implementou (em 2011) um sistema de gestão de pedidos e ocorrências para atendimento dos seus utilizadores preferenciais, que são as Bibliotecas. Este sistema encontra-se organizado em diferentes áreas de intervenção e recebe, por ano, uma média de 650 pedidos que incidem de modo particular nas áreas "Millennium" (45\%) e "Estudo Geral" (41\%).

Importa, ainda, referir que o SIBUC contribui para o Plano Estratégico e de Ação da Universidade de Coimbra, planeando ações e estabelecendo metas a atingir, que são controladas ao longo do período em avaliação. Para o período de 2011-2015 foram definidas 16 ações, totalizando 38 indicadores e com uma taxa de execução considerada satisfatória (75\%). Uma das ações recentemente desenvolvida prende-se com a preparação e envio a toda a comunidade universitária de um inquérito de satisfação aos utilizadores das bibliotecas da UC, tarefa em colaboração com a Divisão de Melhoria Contínua da UC, que será de grande importância para a análise atual dos serviços prestados e para a obtenção de informação sobre a utilização das bibliotecas.

Uma reflexão atenta sobre o estabelecimento das metas, que devem ser metas razoáveis e ter como referência os recursos dispo- 
níveis no Serviço, conduziram a uma atuação diferente no ciclo que se seguiu. Como pontos fortes do Plano desenhado, regista-se o empenho e motivação do Serviço e a experiência adquirida com este processo. Nos pontos fracos, a falta de definição de prioridades com a consequente falta de cumprimento em algumas das ações propostas. Nas oportunidades distinguem-se a boa capacidade de resposta do Serviço e a sua ação que se pauta por integrar novos contributos e por traduzir uma melhoria contínua com base em metodologias de planeamento, gestão e avaliação. Como ameaça, assinala-se a precaridade de alguns dos recursos humanos envolvidos e a reduzida dimensão da equipa.

\section{Perspetivas para o futuro}

A atividade do SIBUC tem sido orientada para a promoção da meIhoria da qualidade dos serviços que as bibliotecas da Universidade de Coimbra prestam à comunidade académica, assim como para a divulgação do seu vasto acervo documental. Foi nesse sentido que se promoveu a gestão centralizada do sistema integrado de gestão de informação bibliográfica, se desenvolveu uma biblioteca digital de fundo antigo e se constituiu o repositório institucional da UC.

No entanto, a rápida evolução tecnológica e a interligação que se tem vindo a estabelecer com as áreas de investigação científica, nomeadamente o acesso aberto a publicação e dados, a preservação digital e curadoria obrigaram a uma redefinição de prioridades e imprimiram alterações significativas na intervenção da equipa do SIBUC.

A adoção de boas práticas e de plataformas comuns, procurando reduzir custos e garantir uma maior proximidade com a população universitária, público-alvo da atividade das bibliotecas da Universidade de Coimbra, foi também uma preocupação presente. Novos desafios têm sido colocados às bibliotecas da UC, que passam pela integração e compatibilidade com plataformas nacionais e interna- 
cionais - entre as quais o RCAAP, a Europeana, o Projeto DRIVER, o Projeto OpenAIRE - e pelo cumprimento das políticas nacionais e internacionais, nomeadamente no domínio da Ciência Aberta. Torna-se necessário apostar no fornecimento de serviços tecnologicamente mais adequados às novas realidades e que tendam a minimizar os efeitos nocivos da redução de meios humanos e materiais atribuídos às bibliotecas e com a capacidade de a responder à maior exigência da sua comunidade académica.

Os atuais sistemas geridos pelo SIBUC necessitam de melhoramentos substanciais, a começar pelo Millennium que desde 2007 sustenta o sistema integrado de gestão de informação bibliográfica e carece de uma atualização tecnológica urgente que permita a disponibilização de novos serviços e a sua interoperabilidade com outros sistemas da UC, nomeadamente o sistema de gestão académica. O Estudo Geral, implementado sobre o software aberto DSpace, tem vindo a assumir um importante papel na renovação de serviços prestados pelas bibliotecas, reforçado pelo cumprimento da legislação em vigor. Também a Resolução do Conselho de Ministros ${ }^{14}$ que define os princípios orientadores para a implementação de uma Política Nacional de Ciência Abertas coloca novos desafios e exige respostas técnicas na organização e implementação de sistemas integrados e interoperáveis de acesso e gestão de informação, para além de tarefas de preservação e curadoria de objetos digitais (publicações e dados). A UC deverá acompanhar as melhores práticas de disponibilização e curadoria de dados científicos, fazendo evoluir o repositório existente neste sentido. A UC Digitalis que agrega os conteúdos digitais da Alma Mater, biblioteca digital de fundo antigo da UC, não permite, de forma eficiente, a incorporação de novas coleções digitais com o nível de autonomia gráfica, de pesquisa e navegação que

14 Resolução do Conselho de Ministros no. 21/2016. Disponível em WWW:< https://dre. pt/home/-/dre/74094659/details/maximized?serie=I\&day=2016-04-11\&date=2016-04-01>. [Cons. 20 abr. 2018]. 
são recomendáveis nestes contextos. Foram, entretanto, feitas várias solicitações de incorporação na UC Digitalis de coleções musicais, cinematográficas, fotográficas ou com temáticas específicas, a que o SIBUC não pode dar uma resposta eficiente e atempada, pelo fato desta infraestrutura carecer duma profunda reformulação técnica.

Da análise da situação atual parece desejável iniciar uma nova fase de modernização de serviços do SIBUC que compreenda propostas de intervenção que passem pela substituição ou melhoria dos sistemas ou adotar outros serviços, como sejam:

- Implementar um CRIS (Current Research Information System) para a UC, com o objetivo de servir as unidades de investigação, garantindo um único local para depósito de documentos, permitir a sincronização com os sistemas ORCID e de gestão de Curricula Vitae e garantir relatórios estatísticos para os órgãos de gestão. Pretende-se, ainda, fazer a integração com o PT-CRIS e o OpenAIRE. Associado a este sistema de gestão de ciência planeia-se desenvolver o registo de APCs (Article Processing Charges), previsto no projeto "IES em Rede", que permitirá reforçar a caraterização dos custos associados à publicação dos resultados de investigação.

- Estudar e preparar uma interface avançada e facilitadora para a construção de coleções digitais, depósito de conteúdos digitais e acesso ao espólio documental da UC, reunindo num único ponto os diversos tipos de conteúdos digitais geridos pelas bibliotecas da UC.

- Criar procedimentos de preservação digital do património bibliográfico e documental da UC (curadoria de objetos digitais para o Estudo Geral e a Alma Mater).

- Criar procedimentos para gestão e curadoria de dados científicos.

- Prestar assessoria técnica à comunidade académica em estudos bibliométricos, análise de citações e impacto da produção científica da UC e dos seus autores. 
- Dinamizar e divulgar o sistema de agregação de conteúdos, o EDS atualmente instalado na UC e cuja utilização deverá ser incentivada junto da comunidade universitária, pelo facto de potenciar o acesso e localização dos recursos existentes nas bibliotecas da UC de forma integrada (catálogo, repositório, bases de dados locais ou de acesso geral).

- Analisar as condições do atual ILS Millennium e estudar soluções alternativas para um futuro ILS da UC que assegure as funcionalidades existentes, garanta a interligação e interoperabilidade com outros sistemas (por exemplo, através de APIs) e permita reduzir significativamente os custos anuais de exploração e licenciamento.

- Acompanhar e participar no projeto de criação de um catálogo integrado das Instituições de Ensino Superior, enquadrado nos projetos da Rede de Bibliotecas do Ensino Superior.

- Participar na nova fase de desenvolvimento da BAES, cujo modelo será reformulado e implicará alterações técnicas profundas, permitindo assegurar de forma mais consistente o acesso aos recursos documentais das universidades e instituto politécnicos que integram o projeto por parte dos estudantes com Necessidades Educativas Especiais.

\section{Conclusão}

Depois da criação do SIBUC como estrutura de gestão e coordenação dos recursos bibliográficos e biblioteconómicos da Universidade de Coimbra, a sua consolidação torna-se fundamental para que prossiga com a sua missão. É certo que o SIBUC tem procurado cumprir com as funções que lhe estão atribuídas e, tendo em conta os seus recursos e dimensão, tem-no realizado com sucesso. No entanto, a falta de uma equipa dedicada e com vínculo estável condiciona a sua atuação e intervenção. O contexto tecnológico, e não só, que motivou o aparecimento do SIBUC, tal como preconizado no Relatório 
das Bibliotecas em 2006, alterou-se no sentido da complexidade, mantendo-se as questões que sustentaram a necessidade de uma estrutura de suporte e coordenação dos serviços de bibliotecas da Universidade, indicadores fundamentais de qualidade e excelência. As exigências e os desafios colocados às bibliotecas e ao SIBUC obrigam a um compromisso sério da própria Universidade. Afirmar uma estratégia de continuidade do trabalho de integração já iniciado e partilhar o conhecimento e experiência adquiridos são condições necessárias para enfrentar o futuro com confiança.

\section{Referências Bibliográficas}

FERREIRA, Carla - A Automatização da(s) Biblioteca(s) da Universidade de Coimbra. Boletim da Biblioteca Geral da Universidade de Coimbra [Em linha]. Vol. 45 (2015), p. 11-88. ISSN 1647-8436. [Cons. 20 mar. 2018]. Disponível em : http://impactum-journals.uc.pt/bbuc/article/view/2184.

MARQUES, João Carlos, coord. - Reorganização e reestruturação das bibliotecas da Universidade de Coimbra : relatório. Coimbra : Universidade de Coimbra, 2006. 83 p.

PRESIDÊNCIA DO CONSELHO DE MINISTROS. Resolução do Conselho de Ministros N. 21/2016. Diário da República I Série. 70 (2016-04-11) p. 1191-3. [Cons. 20 abr. 2018]. Disponível em http://data.dre.pt/eli/resolconsmin /21/2016/04/11/p/dre/ pt/html

REGULAMENTO N.o 488/2009. Regulamento do Serviço Integrado das Bibliotecas da Universidade de Coimbra (SIBUC). Diário da Republica II Série. 238 (2009-12-10) p. $49902-49903$. 